\title{
PINUS MAXIMARTINEZII RZED. (PINACEAE), PRIMER REGISTRO PARA DURANGO, SEGUNDA LOCALIDAD PARA LA ESPECIE
}

\author{
Martha González-Elizondo1,3, M. Socorro GonzÁlez-Elizondo', \\ Lizeth Ruacho-GonzÁlez ${ }^{1}$ y Moisés Molina-Olvera ${ }^{2}$
}

${ }^{1}$ Instituto Politécnico Nacional, Centro Interdisciplinario de Investigación para el Desarrollo Integral Regional, Unidad Durango, Sigma 119, Fraccionamiento 20 de Noviembre II, 34220 Durango, Durango, México.

${ }^{2}$ Comisión Nacional para el Desarrollo de los Pueblos Indígenas, Los Charcos, 34980 El Mezquital, Durango, México.

${ }^{3}$ Autor para la correspondencia: herbario_ciidir@yahoo.com.mx

\section{RESUMEN}

Pinus maximartinezii Rzed. se registra para el sur del estado de Durango, lo que representa la primera población conocida en estado silvestre fuera de la localidad tipo en el sur de Zacatecas. Se presentan datos sobre la nueva población y se discuten las implicaciones para la conservación de esta especie.

Palabras clave: conservación, endemismo, México, nuevo registro, pino azul, Pinus, relaciones evolutivas.

\begin{abstract}
Pinus maximartinezii Rzed. is recorded from southern Durango, the first known record in the wild in addition to the type locality in southern Zacatecas. Data about the new population are presented and the conservation implications for the species are discussed.

Key words: big-cone pinyon, conservation, endemism, evolutionary relations, Mexico, new record.
\end{abstract}

Pinus maximartinezii Rzed. (Pinaceae) fue descrito por Rzedowski (1964) del Cerro de Piñones en la Sierra de Morones, al W de Pueblo Viejo, municipio de 
Juchipila, al sur del estado de Zacatecas y por más de cuatro décadas fue considerado como de distribución restringida a esa localidad (Critchfield y Little, 1966; Little y Critchfield, 1969; Eguiluz Piedra, 1977; Passini, 1982, 1985; García y Eguiluz P., 1986; Perry, 1991; Carvajal y McVaugh, 1992; Styles, 1993; Donahue y Mar-López, 1995; Farjon y Styles, 1997; Farjon et al., 1997; López Mata, 1998; Farjon, 1999, 2005; Frankis, 1999; Ledig et al., 1999, 2001; Arteaga Martínez et al., 2000; Balleza, 2000; García Arévalo y González Elizondo, 2003; Balleza et al., 2005; OjedaZacarías et al., 2006; Sánchez González, 2008). Desde 1964 Rzedowski sugirió la posibilidad de que se encontrara en otros sitios de la región de cañones profundos donde Zacatecas, Jalisco, Nayarit y Durango se unen; la existencia de una segunda población silvestre de Pinus maximartinezii fue corroborada en 2010, presentándose aquí los datos de su ubicación y hábitat.

El segundo sitio de Pinus maximartinezii se encuentra al sur del estado de Durango, cerca del poblado La Muralla, perteneciente a la comunidad indígena de Santa María de Ocotán y Xoconoxtle, municipio de El Mezquital, a 190 km al NW de la localidad tipo (Fig. 1). Santa María de Ocotán y Xoconoxtle es una comunidad O'dam (Tepehuanes del Sur) organizada en 33 unidades administrativas o anexos conformadas por pueblos y rancherías; La Muralla forma parte del anexo de Zalatita. Pinus maximartinezii se desarrolla entre los 1750 y $2260 \mathrm{~m}$ s.n.m. sobre laderas escarpadas con pendientes de 25 a $80 \%$ principalmente en las exposiciones al E, N, y S en una cañada rematada por mesetas angostas, con un desnivel de casi $1000 \mathrm{~m}$ entre el fondo y las partes altas (de 1373 a $2355 \mathrm{~m}$ s.n.m.). El sustrato son litosoles y regosoles sobre roca ígnea. En esta cañada nace el río El Navío, afluente del Huazamota o Jesús María que a su vez es parte de la región hidrológica Lerma-Santiago, a la cual pertenece también el río Juchipila en la localidad tipo en Zacatecas.

Mediante análisis visual in situ así como de cartografía e imágenes de satélite, registros fotográficos e información proporcionada por lugareños, se estima que la población de $P$. maximartinezii en Durango se desarrolla en una superficie de aproximadamente 110 ha, con más de 900 individuos maduros formando manchones dispersos y con densidades que varían entre 1 y 22 individuos/ha. La población de Zacatecas, localizada en un ramal hacia el oriente en el extremo sur de la Sierra Madre Occidental, se ha estimado entre 2000-2500 y 60,548 individuos maduros sobre una superficie de entre 400 ha (Donahue y Mar-López, 1995) y 925 ha (García y Rivera, 1998 citado por Palacios Vázquez, 2008). La cifra de entre 2000 y 2500 individuos (Donahue y Mar-López, op. cit.) se calculó a partir de recorridos y observaciones en las aprox. 400 ha que esos autores estiman que ocupa la especie en 
el Cerro de Piñones, mientras que el cálculo de 60,548 individuos (Lara Rodríguez, 1997) se basó en muestreos de 54 sitios de $1000 \mathrm{~m}^{2}$ en cuatro rodales de $P$. maximartinezii distribuidos en las 415 ha que dicho autor calculó que ocupa $85 \%$ de la población en una superficie total de 3500 ha.

Las plantas de las poblaciones de Durango y Zacatecas presentan gran similitud en características morfológicas (Fig. 2, Apéndice). Las únicas diferencias a este nivel que se han detectado (ala vestigial de la semilla 3-5 mm de largo en

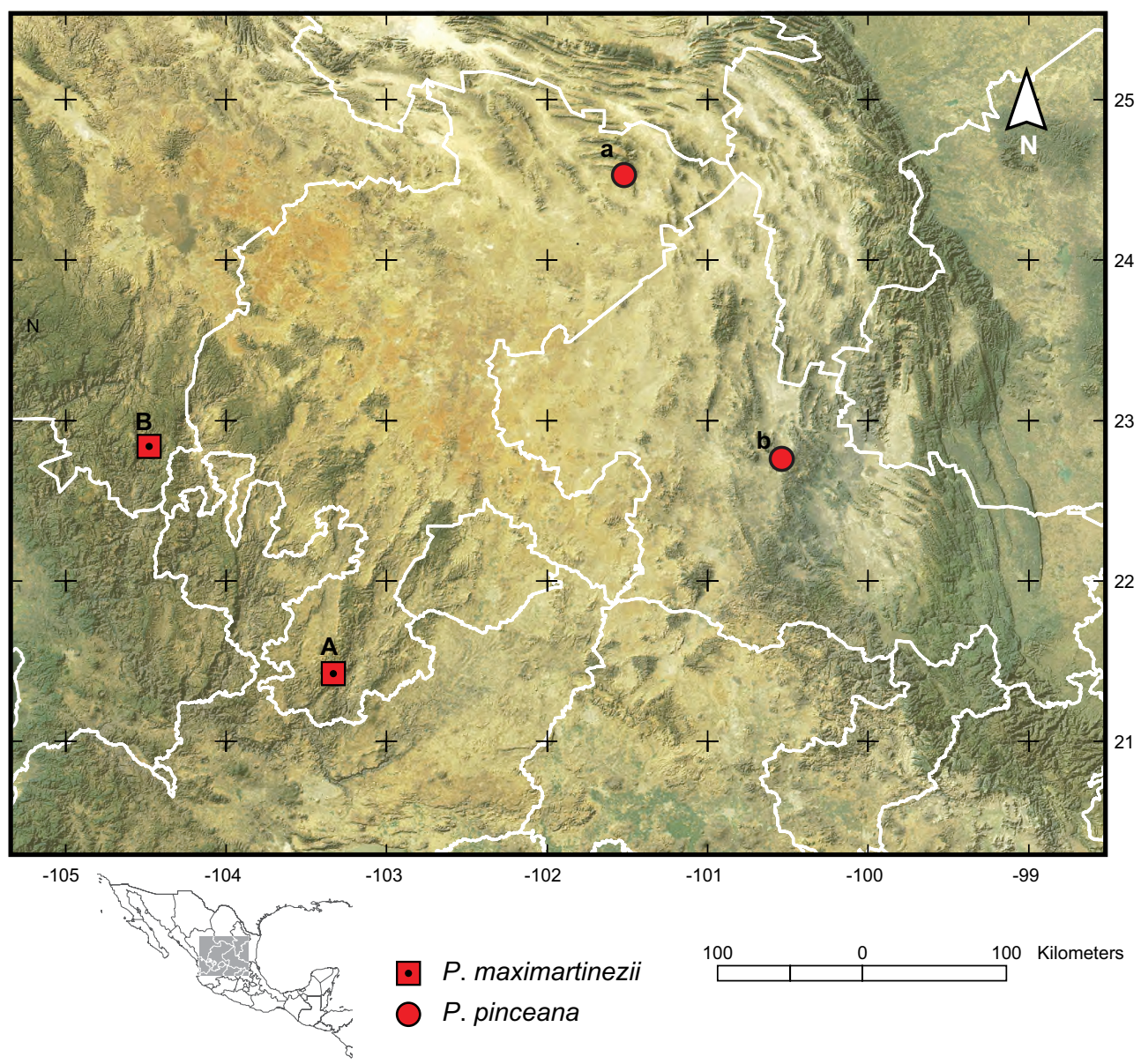

Fig. 1. Distribución conocida de Pinus maximartinezii Rzed. y dos poblaciones de P. pinceana Gordon: A. P. maximartinezii en la localidad tipo, Sierra de Morones, Zac.; B. P. maximartinezii en La Muralla, Dgo.; a. P. pinceana en el Cañón de La Laja, Zac.; b. P. pinceana en el Cañón de La Yesera, S.L.P. 
Durango, 1-2 mm en Zacatecas; hojas 5.5-13 cm de largo en Durango vs 5.8-14.7 $\mathrm{cm}$ en Zacatecas), reflejan probablemente necesidad de mayor muestreo. Un estudio de la variación de caracteres morfológicos en acículas, conos y semillas (García y Eguiluz P., 1986) de las plantas de la localidad de Zacatecas revela que, pese al pe-
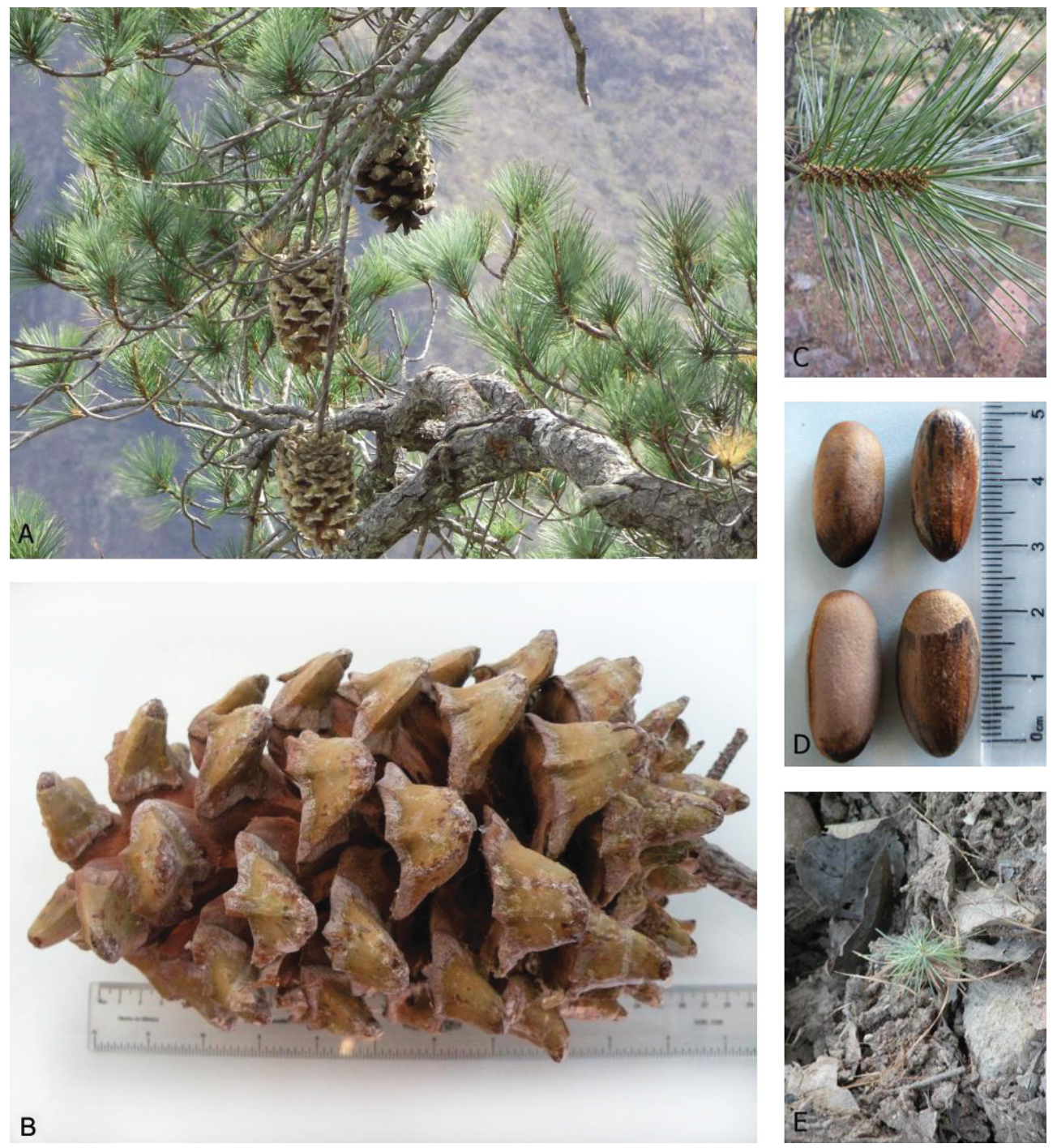

Fig. 2. Pinus maximartinezii Rzed. en la población de La Muralla, Dgo. A. rama y conos; B. cono; C. ramilla; D. semillas; E. plántula. 
queño tamaño de la población, existe una amplia variabilidad morfológica. La misma situación se presenta en las plantas de Durango. En 1985, Passini estimó la edad de los árboles mayores de nueve metros en la población de Juchipila, Zacatecas en alrededor de 220 años; mientras que en 2010, la edad de uno de los individuos más viejos observados en Durango se estimó, mediante conteo de anillos de crecimiento, en por lo menos 250 años.

El hábitat de $P$. maximartinezii es también notablemente similar en ambas localidades en cuanto a características topográficas y elementos dominantes de la vegetación. Tanto en Durango como en Zacatecas las poblaciones son discontinuas, intercaladas entre bosques bajos de Quercus o de Quercus con Pinus lumholtzii B.L. Rob. \& Fernald. En Durango destacan las asociaciones dominadas por Quercus resinosa Liebm. y otras de Quercus spp., con una franja estrecha en las partes más altas donde $P$. maximartinezii se desarrolla en ecotonía con Pinus lumholtzii; en pequeñas áreas $P$. maximartinezii también se presenta como dominante (Fig. 3). Entre los árboles acompañantes, además de $Q$. resinosa y $P$. lumholtzii, se encuentran $Q$. chihuahuensis Trel., Q. praeco Trel., Fraxinus aff. velutina Torr., Arbutus tessellata Sorensen y, en cañadas, Quercus gentryi C.H. Muller. Como elementos arbustivos destacan Salvia sp., Stevia sp., Vernonia sp., Ageratina spp., Opuntia jaliscana Bravo, O. robusta H.L. Wendl. ex Pfeiff., Opuntia sp., Agave sp., Rhus aromatica Aiton, Montanoa sp. y Fraxinus rufescens Torr. En las partes altas se presentan Quercus aff. crassifolia Humb. et Bonpl., Quercus eduardii Trel., Arbutus madrensis S. González, Arctostaphylos pungens H.B.K., Comarostaphylis polifolia (H.B.K.) Zucc. ex Klotzsch, Agave filifera Salm-Dick subsp. schidigera (Lem.) B. Ullrich, Dasylirion sp., Nolina cf. elegans y Muhlenbergia sp. La comparación con los principales elementos acompañantes de $P$. maximartinezii en la localidad tipo (Rzedowski, 1964; Lara Rodríguez, 1997; Balleza, 2000) revela que las especies dominantes fisonómicamente son las mismas ( $P$. lumholtzii, Quercus resinosa). Las especies de afinidad tropical citadas por Rzedowski (1964) no se encontraron conviviendo con P. maximartinezii en Durango, aunque pueden presentarse en el bosque tropical caducifolio en las partes más bajas de la cañada.

Ejemplares examinados. MÉXICO, DURANGO. Municipio El Mezquital,

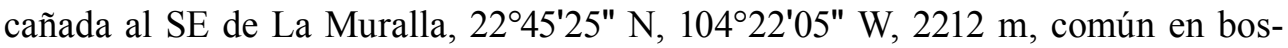
que de Quercus spp.-Pinus maximartinezii, P. lumholtzii, 7 Dic 2010, S. González 7735 con M. González, L. Ruacho, M. Molina (CIIDIR); cañada al SE de La Mura1la, 22 $45^{\prime} 41^{\prime \prime} \mathrm{N}, 104^{\circ} 21^{\prime} 49^{\prime \prime} \mathrm{W}, 2135 \mathrm{~m}$, abundante en bosque de Quercus resinosa, Quercus spp.-Pinus maximartinezii, 8 Dic 2010, S. González 7742 con M. González, L. Ruacho, M. Molina (CIIDIR, ENCB, IEB, MEXU). 
Acta Botanica Mexicana 96: 33-48 (2011)
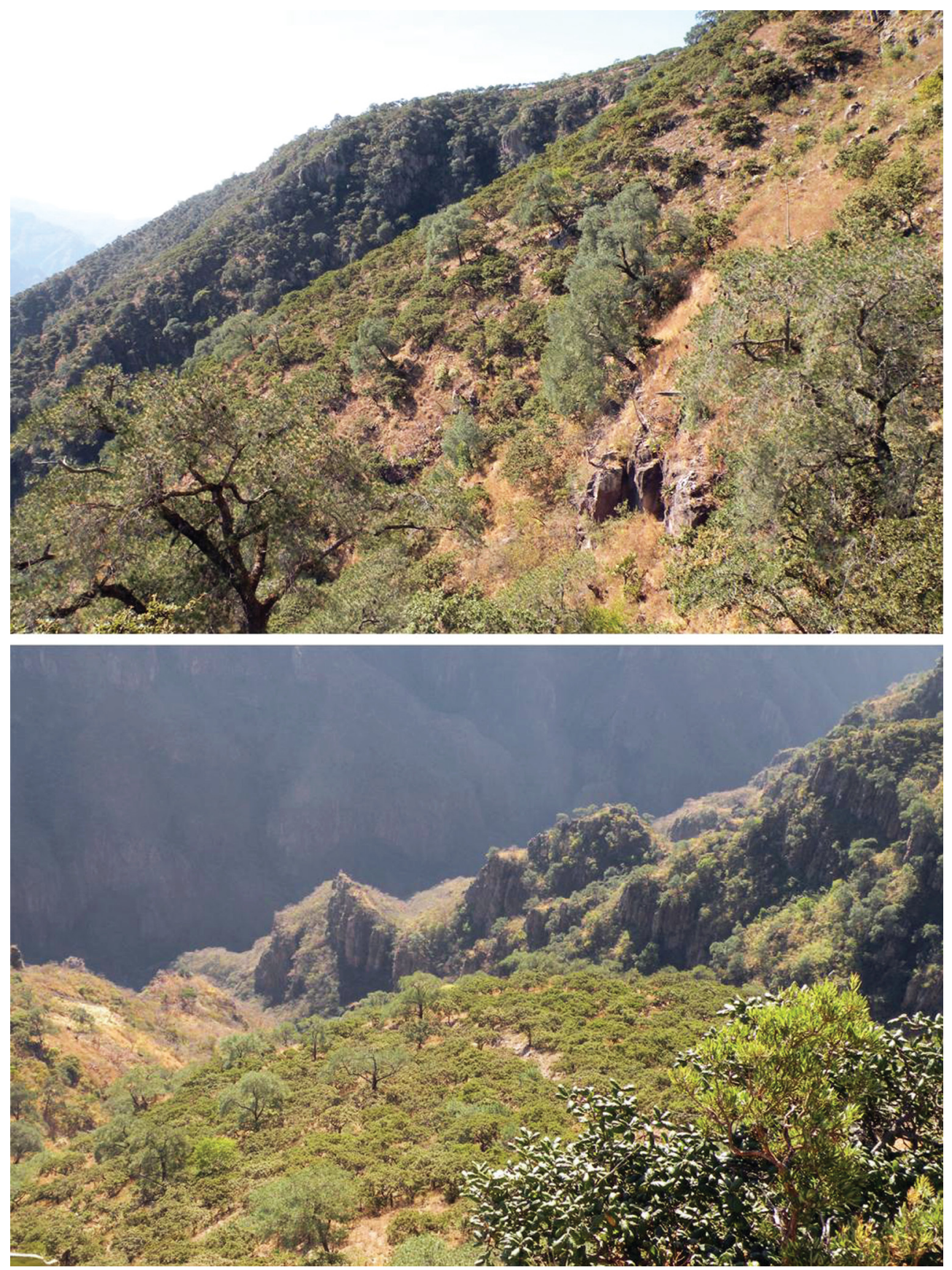

Fig. 3. Hábitat de Pinus maximartinezii Rzed. en la población de La Muralla, Dgo. 
Etnobotánica. Conocido localmente como piñón, las semillas de P. maximartinezii se consumen en La Muralla y poblados cercanos, representando un aporte nutricional a la dieta pobre en la región -recientemente más empobrecida debido a la introducción de comida chatarra- y ocasionalmente se venden en Huejuquilla El Alto, Jalisco. Su sabor es más suave que las del piñón comercial (Pinus cembroides Zucc.). Aunque actualmente no se explota en La Muralla, en otras partes P. maximartinezii es una especie altamente apreciada como ornamental (pino azul) por su follaje suave y de color azulado y por sus ramillas flexibles. Por su adaptabilidad a condiciones de escasa humedad (Rzedowski, 1964) y a suelos someros, esta especie representa una excelente alternativa para reforestar áreas erosionadas en sitios protegidos de los vientos desecantes.

Otros nombres comunes registrados para plantas de la localidad de Zacatecas son: pino, piñón real, pino azul, piñón azul, piñonero de Zacatecas, piñón de Zacatecas, pino de Zacatecas (Eguiluz Piedra, 1978; Arteaga Martínez et al., 2000); algunas formas de llamarlas en la literatura en inglés son: big-cone pinyon, Maxi pinyon y Martínez pinyon.

Estado de conservación. Enlistada como especie endémica y en peligro de extinción en la NOM-059-SEMARNAT 2010 (Anónimo, 2010b) y como "en peligro B1+2bc" en la Lista Roja de Especies Amenazadas (Anónimo, 2010a, 2010b), el descubrimiento de una segunda población de Pinus maximartinezii no modifica su estatus de conservación. El pequeño tamaño de las dos poblaciones conocidas y la baja variabilidad genética que se ha registrado para la población de Zacatecas hacen al árbol altamente susceptible a los cambios ambientales, aunque éstos sean de poca magnitud.

La propiedad donde se encuentra esta población de La Muralla se maneja bajo el régimen de bienes comunales. La cañada es usada para pastoreo de caprinos, aunque no de forma intensiva como ocurre en las mesas de las partes más altas, de manera que sí se observa regeneración y algunos individuos juveniles. Debido al crecimiento irregular del fuste y a la dificultad para llegar a los sitios donde se desarrolla la especie, ésta no se explota para extracción de madera ni de leña, contribuyendo de manera importante a la generación y conservación de suelo, así como alimento y ambiente apropiado para fauna silvestre.

El hábitat de $P$. maximartinezii en Durango se comparte con otra especie de interés para la conservación: la cotorra serrana occidental o guacamaya enana (Rhynchopsitta pachyrhyncha), en peligro de extinción de acuerdo con la NOM- 
059 (Anónimo, 2010b) y la IUCN (Anónimo, 2010a). No se ha encontrado puma, el cual se registra para la localidad de Zacatecas (Durán, 1997 citado por Palacios Vázquez, 2008), pero los comuneros de La Muralla mencionan la presencia de jaguar.

Carvajal y McVaugh (1992) consideraron como una situación extraordinaria el que una especie tan notable y algo aprovechada comercialmente como lo es Pinus maximartinezii no hubiera sido descrita hasta después de 1960, especialmente tomando en cuenta los intensos estudios realizados sobre pinos mexicanos durante el siglo $\mathrm{XX}$, explicando la situación por la distribución tan restringida de la especie y por el hecho de que su ubicación, al igual que la de muchas áreas similares en las montañas occidentales de México, no fuera fácilmente accesible para el viajero casual. Por razones similares pasaron casi cinco décadas del descubrimiento de la especie por Rzedowski (1964) y casi dos de la aseveración de Carvajal y McVaugh para encontrar una segunda población de $P$. maximartinezii, después de una búsqueda propiciada por informes vagos sobre su existencia en el sur de Durango que había resultado infructuosa hasta 2010. Existe la probabilidad de que las nuevas rutas que se abren a través de la Sierra Madre Occidental permitirán encontrar poblaciones adicionales.

Implicaciones evolutivas. Pinus maximartinezii presenta características únicas: tiene 15 a 30 hojas cotiledonares (García y Eguiluz P., 1986), la mayor cantidad registrada para cualquier conífera; las hojas primarias persisten en los individuos juveniles hasta 10 años y llegan a presentarse en ramas laterales de árboles maduros a veces hasta de más de 20 años; y es el piñonero con conos y semillas más grandes en el mundo. Sus relaciones evolutivas han sido abordadas con diferentes enfoques pero no existe aún información concluyente sobre su ascendencia, aunque diversas líneas de investigación sugieren que la especie es muy cercana a $P$. pinceana Gordon. Rzedowski (1964) hipotetizó que la población de Zacatecas podría constituir un vestigio de una distribución más amplia (paleoendemismo), relacionándolo con $P$. pinceana y $P$. cembroides; las afinidades morfológicas entre los conos y semillas de P. maximartinezii y los de pinos de la sección Gerardianae Lond. de los Himalayas fueron notadas por Rzedowski (1964), Malusa (1992) y Farjon (1996) e interpretadas como resultado de posible convergencia evolutiva, lo que se confirma en recientes esquemas filogenéticos obtenidos mediante estudios moleculares (Gernandt et al., 2003, 2005; Zhang y Li, 2004).

Las relaciones evolutivas de las especies de Pinus subgénero Strobus en general permanecen sin definirse bien a pesar de los esfuerzos combinados basados en 
análisis de nrITS -región del espaciador interno transcrito del ADN nuclear ribosomal- y de cpDNA -ADN de cloroplasto- (Gernandt et al., 2003; Syring et al., 2007), pero varios trabajos (Pérez de la Rosa et al., 1995; Gernandt et al., 2001, 2003, 2005) indican que la relación más cercana de Pinus maximartinezii es con Pinus pinceana. Aunque con fundamento en las características de las semillas y los cotiledones, $P$. pinceana parece estar más vinculada con otros piñoneros que con $P$. maximartinezii (Eguiluz et al., 1985, citados en Ledig et al., 2001), ambos taxa comparten otras similitudes morfológicas, químicas y genéticas y se consideran especies hermanas (Pérez de la Rosa et al., 1995; Gernandt et al., 2001, 2003, 2005; Piñero, 2005).

Con base en rasgos morfológicos, ambas especies forman un grupo junto con P. rzedowskii Madrigal \& Caballero, P. nelsonii G.R. Shaw y P. gerardiana Wall. ex D. Don (Malusa, 1992), pero los datos moleculares revelan que $P$. nelsonii forma parte de una subsección monotípica (Nelsoniae van der Burgh) y que P. gerardiana pertenece a la subsección Gerardianae Loud., mientras que $P$. maximartinezii, $P$. pinceana y $P$. rzedowskii se agrupan como parte de la subsección Cembroides Engelm., aunque no muy cercanas al piñonero mexicano común ( $P$. cembroides) (Gernandt et al., 2003, 2005). Las tres subsecciones se clasifican en la Sección Parrya Mayr del subgénero Strobus Lemmon.

Pinus maximartinezii y $P$. pinceana son similares además en la composición de monoterpenos, predominando en ambas el limoneno (Zavarin y Snajberk, 1987). Comparten secuencias de ADN de cloroplasto (Pérez de la Rosa et al., 1995) y de la región del ITS, aunque esta última es tan heterogénea en pinos que muchas veces las copias divergentes en individuos de una misma especie no forman un grupo monofilético, sino que se intercalan con las de otras plantas de la misma subsección (Gernandt et al., 2001); comparten también varios loci polimórficos, por lo que Ledig et al. (2001) han postulado a $P$. pinceana como probable progenitor de $P$. maximartinezii. Otros trabajos sugieren relaciones entre estas dos especies y con $P$. rzedowskii. Un esquema filogenético basado en una región del ADN ribosomal nuclear agrupa a $P$. maximartinezii con $P$. pinceana y con $P$. rzedowskii (Liston et al., 1999), al igual que ocurre en otras dos que atañen los pinos piñoneros obtenidas con el modelo de parsimonia y el de máxima verosimilitud con fundamento en secuenciación de distintas regiones del ADN de cloroplasto (Gernandt et al. 2007), en las que $P$. maximartinezii aparece asociado a $P$. pinceana y ambas especies aparecen relacionadas con $P$. rzedowskii (por lo que actualmente no se reconoce la subsección Rzedowskiae Carv.). La relación con P. rzedowskii, una planta con características intermedias entre los pinos del subgénero Pinus y los del subgénero Strobus, parece corroborar la hipótesis de Rzedowski (1964) de que P. maximarti- 
nezii podría descender de antecesores que marcaron el paso evolutivo de los pinos diplostélicos a los haplostélicos basado en el hecho de que el haz vascular en Pinus maximartinezii, aunque único, está dividido en dos porciones simétricas por una hilera de células de esclerénquima, lo que posiblemente representaría el vestigio de la existencia de dos haces vasculares. La presencia de un ala vestigial en las semillas de $P$. maximartinezii es otro punto a favor de la hipótesis de relación con antecesores de posición intermedia entre los dos subgéneros.

De acuerdo con Ledig et al. (1999), hace apenas cuatro o cinco generaciones (menos de 1000 años) la población de P. maximartinezii de Zacatecas pudo haber sido reducida a un cuello de botella extremo y probablemente la actual proviene de una sola semilla, de donde resurgió rápidamente. Los autores basan su hipótesis en la marcada reducción en alelos en loci polimórficos que se encuentra en $P$. maximartinezii (máximo dos por locus, a diferencia de otros pinos en donde predominan isoenzimas multialélicas), con la mayoría de los alelos en esos loci agrupados a frecuencias intermedias, y un marcado desequilibrio gamético. Ledig et al. (2001) encontraron que la distancia genética entre $P$. maximartinezii y $P$. pinceana del Cañón de La Yesera, S.L.P., el sitio geográficamente más cercano a la población de $P$. maximartinezii de Zacatecas, está entre las más altas entre las poblaciones de $P$. pinceana estudiadas, mientras que la menor distancia se presenta entre $P$. maximartinezii y una población de $P$. pinceana del extremo norte de Zacatecas (Cañón de La Laja). $\mathrm{Su}$ interpretación fue que, a pesar de que la población de $P$. pinceana de La Yesera es la más cercana geográficamente a la de $P$. maximartinezii (de Zacatecas), ambas especies están en diferentes cordilleras, separadas por la Meseta Central árida de México, mientras que la menor distancia genética es con $P$. pinceana del Cañón de La Laja, ya que esa zona está conectada con el sur de la Sierra Madre Occidental por una ruta de migración más directa "ya que las provincias morfotectónicas de la Sierra Madre Occidental y la Sierra Madre Oriental están en contacto en el extremo norte de la Sierra Madre Oriental (Ferrusquía-Villafranca, 1993)”. Este argumento no es muy válido para considerar una ruta de migración entre la Sierra de Morones (Fig. 1 A) y el Cañón de La Laja (Fig. 1 a), ya que ambos sitios están separados por una zona de la Altiplanicie árida aún más amplia que la que separa a la Sierra de Morones y La Yesera (Fig. 1 b), pero toma más sentido con la existencia de una localidad de $P$. maximartinezii ubicada más al norte (Fig. 1 B).

El descubrimiento de la población de $P$. maximartinezii en Durango, inmersa en las quebradas del macizo de la Sierra Madre Occidental pero con una ruta de migración más corta hacia la población de $P$. pinceana más cercana genéticamente, y con base en la hipótesis de que la población de $P$. maximartinezii de Zacatecas 
pudiera haber surgido hace pocas generaciones a partir de una semilla (Ledig et al., 1999), deja abierta la posibilidad de que la población de Durango sea anterior a la de Zacatecas. Ambos rodales se localizan en una misma región hidrológica (Lerma-Santiago), de tal manera que cabe la posibilidad de una dispersión por aves hace pocos cientos de años. La persistencia de hojas primarias por varios años en esta especie es un rasgo de heterocronía paedomórfica (Cronquist, 1988) que podría reflejar un mecanismo de adaptación rápida a un medio fluctuante.

Las implicaciones de conocer una segunda población de $P$. maximartinezii son de gran interés biogeográfico, ecológico y para la conservación de esta enigmática especie. Independientemente de que $P$. maximartinezii represente a un paleorelicto o un neorelicto, y ya sea que la población de Zacatecas sea ancestral o sea derivada de la de Durango, la cruza artificial de individuos provenientes de ambos sitios podría ayudar a incrementar su variación genética. Se requieren estudios para saber si hay riesgo de depresión exogámica y saber qué tan sanos son los rodales, pero los datos recabados sobre P. maximartinezii de Zacatecas (López Mata, 1998) indican que esa población es saludable, con buena estabilidad demográfica, y que el peligro para la especie se deriva más bien de las amenazas a su hábitat, de manera que la cruza de individuos de ambas zonas podrá ayudar a fortalecer su poza genética y a desarrollar nuevas estrategias de conservación.

\section{AGRADECIMIENTOS}

Margarito Mendoza Salvador y los Sres. Alfonso Cervantes Cervantes, Félix Salvador Mendoza, Mario Soto Salvador, Fernando Martínez Cervantes, Marcelino Salvador Mendoza, Paulino Salvador Soto, Leonardo Salvador Soto, Feliciano Mendoza Salvador y Adolfo Orozco Solís nos guiaron en la búsqueda de poblaciones. El Sr. Florencio Soto Flores y el Ing. Gabino Cumplido Muñoz proporcionaron información sobre el pino. El Dr. Jerzy Rzedowski nos apoyó con comentarios sobre P. maximartinezii y su hábitat, el Dr. Jorge Nocedal Moreno con la identificación de las imágenes de la cotorra serrana y el Dr. Rafael F. del Castillo Sánchez con comentarios sobre reproducción exogámica. Los comentarios de dos revisores anónimos permitieron mejorar el manuscrito. A la Comisión de Operación y Fomento de Actividades Académicas del Instituto Politécnico Nacional se agradecen los estímulos a la investigación. La información presentada es parte de los resultados del proyecto IPN 20101216, Fitodiversidad y Ecosistemas de la Sierra Madre Occidental. 


\section{LITERATURA CITADA}

Anónimo. 2010a. International Union for Conservation of Nature (IUCN) red list of threatened species: version 2010.4. Consultado el 10 de diciembre de 2010. http:// www.iucnredlist.org

Anónimo. 2010b. Norma Oficial Mexicana NOM-059-ECOL-2010. Protección ambiental -especies nativas de México de flora y fauna silvestres- categorías de riesgo y especificaciones para su inclusión, exclusión o cambio- lista de especies en riesgo. Diario Oficial de la Federación, segunda sección, México, D.F. pp. 1-77.

Arteaga Martínez, B., H. García Rodríguez y J. G. Rivera Medrano. 2000. Piñón grande, Pinus maximartinezii Rzedowski. Universidad Autónoma Chapingo, División de Ciencias Forestales. Chapingo, México. 134 pp.

Balleza C., J. J. 2000. Flora del Cerro de Piñones, Juchipila, Zacatecas, México. Informe final del Proyecto L114. Facultad de Agronomía, Universidad Autónoma de Zacatecas. Cieneguillas, Zacatecas. $10 \mathrm{pp}$.

Balleza, J. J., J. L. Villaseñor y G. Ibarra-Manríquez. 2005. Regionalización biogeográfica de Zacatecas, México, con base en los patrones de distribución de la familia Asteraceae. Rev. Mex. Biodiv. 76(1): 71-78.

Carvajal, S. y R. McVaugh. 1992. Pinus. In: McVaugh, R., W. R. Anderson (eds.). Gymnosperms and Pteridophytes. Flora Novo-Galiciana 17. University of Michigan Herbarium. Ann Arbor, Michigan. 467 pp.

Critchfield, W. B. y E. L. Little, Jr. 1966. Geographic distribution of the pines of the World. United States Department of Agriculture, Forest Service Miscellaneous Publication 991. Washington, D.C. 97 pp.

Cronquist, A. 1988. The evolution and classification of flowering plants. 2nd. ed. The New York Botanical Garden. Bronx, New York. 555 pp.

Donahue, J. K. y C. Mar-López. 1995. Observations on Pinus maximartinezii Rzedowski. Madroño 42(1): 19-25.

Eguiluz Piedra, T. 1977. Los pinos del mundo. Departamento de Bosques, Escuela Nacional de Agricultura. Chapingo, México. Pub. Esp. 1: 1-75.

Eguiluz Piedra, T. 1978. Ensayo de integración de conocimientos sobre el género Pinus en México. Tesis de licenciatura. Universidad Autónoma Chapingo. Chapingo, México. $623 \mathrm{pp}$.

Farjon, A. 1996. Biodiversity of Pinus (Pinaceae) in Mexico: speciation and palaeoendemism. Bot. J. Linn. Soc. 121: 365-384.

Farjon, A. 1999. Bigcone pinyon pine (Pinus maximartinezii Rzed.). In: Farjon, A. y C. N. Page (compilers). Conifers: status survey and conservation action plan. Species Survival Commission Conifer Specialist Group, International Union for Conservation of Nature and Natural Resources. Gland, Switzerland. pp. 101-102.

Farjon, A. 2005. Pines: drawings and descriptions of the genus Pinus. 2nd. ed. Brill NV. Leiden, The Netherlands. $235 \mathrm{pp}$.

Farjon, A. y B. T. Styles. 1997. Pinus (Pinaceae). Flora Neotropica Monograph 75. The New York Botanical Garden. Bronx, New York. 239 pp. 
Farjon, A., J. A. Pérez de la Rosa y B. T. Styles. 1997. A field guide to the pines of Mexico and Central America. The Royal Botanic Gardens. Kew. U.K. 151 pp.

Frankis, M. P. 1999. Pinus maximartinezii. In: Earle, C. J. 2009. The Gymnosperm Database. Consultado el 20 de diciembre de 2010. http://www.conifers.org/pi/pin/ maximartinezii.htm

García N., R. M. y T. Eguiluz P. 1986. Variación morfológica de Pinus maximartinezii Rzedowski. Rev. Chapingo 11(52-53): 41-49.

García Arévalo, A. y M. S. González Elizondo. 2003. Pináceas de Durango. 2da. ed. Comisión Nacional Forestal-Instituto de Ecología, A.C. Durango, Durango. 187 pp.

Gernandt, D. S., A. Liston y D. Piñero. 2001. Variation in the nrDNA ITS of Pinus subsection Cembroides: implications for molecular systematic studies of pine species complexes. Mol. Phylogenet. Evol. 21: 449-467.

Gernandt, D. S., A. Liston y D. Piñero. 2003. Phylogenetics of Pinus subsections Cembroides and Nelsoniae inferred from cpDNA sequences. Syst. Bot. 28: 657-673.

Gernandt, D. S., G. Geada López, S. Ortiz García y A. Liston. 2005. Phylogeny and classification of Pinus. Taxon 54: 29-42.

Gernandt, D. S., O. Zerón Flores e I. Goyenechea. 2007. Inferencia filogenética mediante secuencias de DNA: un ejemplo con los pinos piñoneros. In: Contreras-Ramos, A., C. Cuevas Cardona, I. Goyenechea y U. Iturbe (eds.). La sistemática, base del conocimiento de la biodiversidad. Universidad Autónoma del Estado de Hidalgo. Pachuca, Hidalgo. pp. 55-65.

Lara Rodríguez, E. A. 1997. Caracterización y evaluación del bosque natural del pino azul (Pinus maximartinezii Rzed.) en el Cerro de Piñones de Juchipila, Zacatecas. Tesis de maestría en ciencias. Universidad Autónoma de Nuevo León. Monterrey, Nuevo León. 52 pp.

Ledig, F. T., M. T. Conkle, B. Bermejo, T. Eguiluz, P. Hodgskiss, D. R. Johnson, y W. S. Dvorak. 1999. Evidence for an extreme bottleneck in a rare Mexican pinyon: genetic diversity, disequilibrium, and the mating system in Pinus maximartinezii. Evolution 53(1): 91-99.

Ledig, F. T., M. A. Capó-Arteaga, P. D. Hodgskiss, H. Sbay, C. Flores-López, M. T. Conkle y B. Bermejo-Velázquez. 2001. Genetic diversity and the mating system of a rare Mexican piñon, Pinus pinceana, and a comparison with Pinus maximartinezii (Pinaceae). Amer. J. Bot. 88: 1977-1987.

Liston, A., W. A. Robinson, D. Piñero y E. R. Alvarez-Buylla. 1999. Phylogenetics of Pinus (Pinaceae) based on nuclear ribosomal DNA internal transcribed spacer region sequences. Mol. Phylogenet. Evol. 11: 95-109.

Little, E. L. Jr. y W. B. Critchfield. 1969. Subdivisions of the genus Pinus (Pines). United States Department of Agriculture, Forest Service Miscellaneous Publication 1144. Washington, D.C. 18 pp.

López Mata, L. 1998. Regeneración, crecimiento y dinámica poblacional del pino azul Pinus maximartinezii Rzedowski. Informe final del proyecto H140. Comisión Nacional para el Conocimiento y Uso de la Biodiversidad. México, D.F. 32 pp.

Malusa, J. 1992. Phylogeny and biogeography of the pinyon pines (Pinus subsect. Cembroides). Syst. Bot. 17: 42-66. 
Ojeda-Zacarías, M. C., H. A. Luna-Olvera, L. H. Morales-Ramos, M. J. Verde-Star, T. E. Torres-Cepeda, B. Pereyra-Alférez, L. Iracheta-Donjuan, E. Olivares-Sáenz, R. Salazar-Sáenz, E. Cárdenas-Cerda. 2006. Multiplicación in vitro del Piñón Azul (Pinus maximartinezii Rzedowski). Phyton 75: 109-113.

Palacios Vázquez, A. L. 2008. Cultivo in vitro de Pinus maximartinezii Rzedowski. Tesis Ingeniero en Restauración Forestal. Universidad Autónoma Chapingo. Chapingo, México. 54 pp.

Passini, M.-F. 1982. Les forêts de Pinus cembroides au Mexique. Editions Recherche sur les Civilisations. Paris. 372 pp.

Passini, M.-F. 1985. Structure et régénération des formations ligneuses à Pinus maximartinezii Rzed., Mexique. Bull. Soc. Bot. Franc. 32: 327-339.

Pérez de la Rosa, J., S. A. Harris y A. Farjon. 1995. Noncoding chloroplast DNA variation in Mexican pines. Theor. Appl. Genet. 91: 1101-1106.

Perry, J. P. 1991. The pines of Mexico and Central America. Timber Press. Portland, Oregon. $231 \mathrm{pp}$.

Piñero, D. 2005. Estructura genética y conservación. El caso de los pinos de México. Biodiversitas 61: 8-11.

Rzedowski, J. 1964. Una especie nueva de pino piñonero del estado de Zacatecas (México). Ciencia 23: 17-20.

Sánchez González, A. 2008. Una visión actual de la diversidad y distribución de los pinos de México. Madera y Bosques 14(1): 107-120.

Styles, B. T. 1993. Genus Pinus: a Mexican purview. In: Bye, R., A. Lot, J. Fa (eds.). Biological diversity of México: origins and distribution. Oxford University Press. Oxford, U.S.A. pp. 397-420.

Syring, J., K. Farrell, R. Businsky, R. Cronn y A. Liston. 2007. Widespread genealogical nonmonophyly in species of Pinus subgenus Strobus. Syst. Biol. 56(2): 163-181.

Zavarin, E. y K. Snajberk. 1987. Monoterpene differentiation in relation to the morphology of Pinus culminicola, Pinus nelsonii, Pinus pinceana and Pinus maximartinezii. Bioch. Syst. Ecol. 15: 307-312.

Zhang, Z. Y. y D. Z. Li. 2004. Molecular phylogeny of section Parrya of Pinus (Pinaceae) based on chloroplast matK gene sequence data. Acta Bot. Sin. 46(2): 171-179. 


\section{APÉNDICE}

Descripción de Pinus maximartinezii Rzed.

Pinus maximartinezii Rzed., Ciencia 23: 17. pl. 2. 1964.

Tipo: Zacatecas, Cerro de Piñones, $4 \mathrm{~km}$ al W de Pueblo Viejo, municipio de Juchipila, 25 Ene 1964, Rzedowski 18258 (holotipo: MEXU; isotipos: ENCB (2), K, MEXU (2), $\mathrm{MICH})$.

Árbol de 5 a 13(-16) m de alto, tronco de 30-60 cm DAP, frecuentemente ramificado a uno o dos metros del suelo, no recto. Corteza de árboles jóvenes lisa, de color gris claro, en árboles maduros en placas irregularmente cuadriculadas, café grisácea o café oscura exteriormente y café rojiza interiormente. Copa amplia, redondeada o irregular, de 4 a 11 $\mathrm{m}$ de diámetro, el follaje de los árboles maduros verde azuloso pálido o verde grisáceo a la distancia. Ramas extendidas, irregularmente espaciadas; ramillas largas y flexibles, algo colgantes, gris pálido lustroso, rara vez café rojizas. Hojas primarias solitarias, algo planas, de 3-5 $\mathrm{cm}$ de largo de poco más de $1 \mathrm{~mm}$ de ancho, de color verde azul cenizo, muy pálidas, persistiendo por varios años en individuos juveniles y en ramas nuevas en árboles maduros. Hojas maduras en fascículos de 5 (rara vez 4 o 3), aglomeradas hacia la extremidad de las ramillas, la vaina 7-8 $\mathrm{mm}$ de largo, castaño claro brillante, decidua en la primera estación, la parte basal persistente y en forma de roseta constituida por unas cinco brácteas unidas y enroscadas, 1-2 mm de largo, de color castaño rojizo; hojas 5.5-14.7 cm de longitud, de sección triangular, 0.5-1 mm de ancho y 0.4-0.6 mm de grosor, flexibles, con márgenes enteros o con algunos dientecillos irregulares, la cara exterior con superficie verde brillante, sin estomas, las caras interiores con dos o tres hileras estomatales blancas dando coloración glauca. Conos (estróbilos femeninos) masivos, péndulos sobre pedúnculos delgados 1-3 cm de largo y 6-8 mm de grueso, ovoides a elipsoides, (10.5-)15-25(-27) cm de largo, (9.2-)12-14(-17) $\mathrm{cm}$ de ancho, de color verde esmeralda cuando inmaduros, madurando castaño pálido a castaño gris, muy resinosos, de 1.3 a $2 \mathrm{~kg}$ cuando verdes; escamas 60 a 110, gruesas y lignificadas, hasta de $7.6 \mathrm{~cm}$ de largo, $5.6 \mathrm{~cm}$ de ancho y $3 \mathrm{~cm}$ de grueso, cóncavas en la cara superior, la cavidad de la semilla profunda; apófisis piramidal, irregularmente tetragonal a hexagonal, muy protuberante, en las escamas medias hasta de $5.1 \mathrm{~cm}$ de ancho, $3 \mathrm{~cm}$ de grueso (incluyendo el umbo), y $2.5 \mathrm{~cm}$ de largo o más, transversalmente aquillada, de color castaño algo brillante; umbo dorsal, tetra o hexagonal, café claro algo lustroso, con cúspide protuberante y gruesa frecuentemente curvada hacia afuera, de color castaño oscuro, en las escamas medias hasta de $1.8 \mathrm{~cm}$ de ancho, $1.2-1.5 \mathrm{~cm}$ de largo y $0.8 \mathrm{~cm}$ de alto; espina nula 
o diminuta. Los conos maduran a partir de agosto, tres a cuatro años después de la polinización. Semillas muy grandes, 20-28 mm de longitud (las mayores entre todos los pinos), (8-)10-12(-14) $\mathrm{mm}$ de ancho y 7-10 $\mathrm{mm}$ de grosor, oblongas a ovoide-oblongas, de color castaño claro a castaño rojizo o negruzcas, aparentemente sin ala ya que el ala vestigial (1-5 $\mathrm{mm}$ de largo) queda adherida a la escama cuando cae la semilla, con cubierta externa dura, 2 $\mathrm{mm}$ de grosor, la interna delgada y fácilmente desprendible; almendra blanca o ligeramente castaña, 18-24 mm de largo, 5-7 $\mathrm{mm}$ de ancho, aceitosa y de sabor resinoso y agradable. Embrión con 15 a 30 cotiledones.

Anatomía foliar: Haz vascular solitario pero frecuentemente dividido por una línea media de células de refuerzo; hipodermis casi homomorfa formada por una hilera continua de células de pared gruesa, a veces una segunda hilera en los ángulos e irregularmente sobre otras partes; canales resiníferos usualmente dos, externos, sobre la cara exterior de la hoja; cilindro central circular, células endodermales de pared delgada; haz vascular uno, pero frecuentemente dividido en dos partes por una hilera vertical media de células de refuerzo (Rzedowski, 1964). 